\title{
THE IN VITRO HYDRODYNAMIC CHARACTERISTICS OF THE PORCINE PULMONARY VALVE AND ROOT WITH REGARD TO THE ROSS PROCEDURE
}

Zsolt L. Nagy, MD

John Fisher, $\mathrm{PhD}^{\mathrm{b}}$

Peter G. Walker, $\mathrm{PhD}^{\mathrm{b}}$

Kevin G. Watterson, FRACS ${ }^{\mathrm{a}}$
Objective: The hydrodynamic parameters and leaflet motion of the porcine pulmonary root and valve and the performance of the pulmonary autograft implanted in subcoronary position or as a free-standing root were investigated at systemic and pulmonary pressures in vitro.

Methods: Ten fresh pulmonary and aortic roots (anulus diameter, 20-25 mm) were tested in a pulsatile flow simulator. Five free-sewn pulmonary valves were implanted in aortic roots in the subcoronary position, and 5 pulmonary roots were implanted as free-standing roots. The external diameter of the roots was measured at the sinotubular junction in a pressure range of 0 to 120 $\mathrm{mm} \mathrm{Hg}$. The transvalvular gradient and regurgitation were measured, and the effective orifice area was calculated. The leaflet motion was recorded on video tape.

Results: The fresh pulmonary roots were more compliant than their aortic counterparts $(33 \% \pm 3.0 \%$ vs $7 \% \pm 1.5 \%$ with dilatation at $0-30 \mathrm{~mm} \mathrm{Hg}$ and $46 \% \pm 8.4 \%$ vs $35 \% \pm 7.8 \%$ with dilatation at $0-120 \mathrm{~mm} \mathrm{Hg}$ ). The pulmonary roots had a lower pressure drop at systemic than at pulmonary pressures. The pressure drops of the pulmonary roots were also lower than those of the aortic roots in the systemic pressure range. The leaflet opening of the pulmonary valve was triangular, with low bending deformation at all pressures. Implanting the free-sewn pulmonary valve in the subcoronary position or the pulmonary root as a free-standing root did not affect the hydrodynamic parameters and leaflet motion adversely.

Conclusion: The pulmonary valve and root could easily withstand aortic pressures in vitro. A biphasic dilatation curve ensures that higher pressures did not overdilate the pulmonary root. Moreover, valve performance was better at systemic pressures. (J Thorac Cardiovasc Surg 2000;120:284-9)
S ince 1967, when Ross ${ }^{1}$ reported the first successful clinical use of the pulmonary autograft for aortic valve replacement, the Ross procedure has become a widely accepted treatment for aortic valve disease, especially in young patients. In the last 3 decades, refinements of the surgical technique have helped to reduce hospital mortality and improve the early and midterm results to a rate comparable with that achieved with conventional aortic valve replacement. ${ }^{2-4}$ In expe-

From the Yorkshire Heart Centre, ${ }^{a}$ Leeds General Infirmary, and the School of Mechanical Engineering, ${ }^{\mathrm{b}}$ University of Leeds, Leeds, United Kingdom.

Supported by the National Heart Research Fund and National Lottery Charities Board.

Received for publication Nov 3, 1999; revisions requested Jan 17, 2000; revisions received March 3, 2000; accepted for publication March 28, 2000. rienced hands the overall hospital mortality for the Ross procedure is about $2.5 \%$, which is not significantly different from that for conventional aortic valve replacement. ${ }^{5}$ In 1997, Chambers and colleagues ${ }^{6}$ published the long-term results of the pioneer series, which showed a $62 \%$ overall freedom from reoperation 20 years after surgery (75\% for the autograft and $80 \%$ for the pulmonary homograft) and only 3 cases of structural deterioration of 131 autografts. The biggest advan-

\footnotetext{
Address for reprints: Kevin G. Watterson, FRACS, Consultant Cardiothoracic Surgeon, Yorkshire Heart Centre, Calverley St, Leeds LS1 3EX, United Kingdom (E-mail: kevingw@ulth.northy.nhs.uk)

Copyright (C) 2000 by The American Association for Thoracic Surgery

0022-5223/2000\$12.00+ $0 \quad \mathbf{1 2 / 1 / 1 0 7 4 7 3}$

doi:10.1067/mtc. 2000.107473
} 
tages of the Ross procedure are long-term durability without the need for anticoagulation, a very low incidence of valve-related complication (thromboembolism and endocarditis), and proven growth potential. ${ }^{7}$ However, concerns remain about the pulmonary valve performance and durability at systemic pressures.

To address these concerns, we investigated the hydrodynamic characteristics and leaflet motion of the pulmonary and aortic valves, as well as those of the pulmonary autograft implanted in the subcoronary position or as a free-standing root.

\section{Methods}

Ten fresh porcine aortic and pulmonary roots were investigated.

Pulmonary and aortic roots. The roots were dissected out from fresh pig hearts, stored at $4^{\circ} \mathrm{C}$ in normal saline solution, and used within 24 hours. The right and left coronary arteries were ligated on the aortic roots. The external diameter of both the aortic and pulmonary roots was measured at the sinotubular junction at hydrostatic pressures of $0,30,60,80,100$, and $120 \mathrm{~mm} \mathrm{Hg}$ by means of digital vernier callipers. The anulus size was measured on all the pulmonary and aortic roots by passing an obturator through from the ventricular side. The anulus diameter of both the aortic and pulmonary roots was in the range of 20 to $25 \mathrm{~mm}$.

Technique of autograft implantation. Five autografts were implanted in a subcoronary position by a freehand suturing technique, and 5 others were implanted as a freestanding autograft root. Each pulmonary valve or root was implanted in a matching size aortic root.

Freehand subcoronary implantation. The right ventricular outflow tract muscle was thinned off to approximately $2 \mathrm{~mm}$ in thickness and trimmed $2 \mathrm{~mm}$ below the nadir of the cusps. Then all 3 sinuses were excised, and the remnant of the pulmonary artery wall was trimmed approximately $2 \mathrm{~mm}$ above the commissures. The aortic valve leaflets were excised. Thereafter, the lower rim of the autograft was sewn just beneath the aortic anulus from the ventricular side by using 40 continuous polypropylene sutures in such a way that the autograft's commissures were in alignment with the aortic commissural attachment. Then a 5-0 polypropylene suspending stitch was placed at each commissure and through the aortic wall. The upper row of subcoronary continuous sutures (50 polypropylene) was placed through the scalloped upper margin of the autograft and through the half thickness of the aortic wall, leaving the coronary ostia clear.

Free-standing autograft root implantation. The right ventricular outflow tract muscle was thinned and trimmed in the same way as for the subcoronary implantation. Then the aortic valve leaflets and all 3 sinuses were excised from the host aortic roots. The remnant of the aortic wall was trimmed off approximately 2 to $3 \mathrm{~mm}$ above the commissures to get a scalloped shaped host anulus preparation. The pulmonary root cylinder was then implanted subannularly with continu-
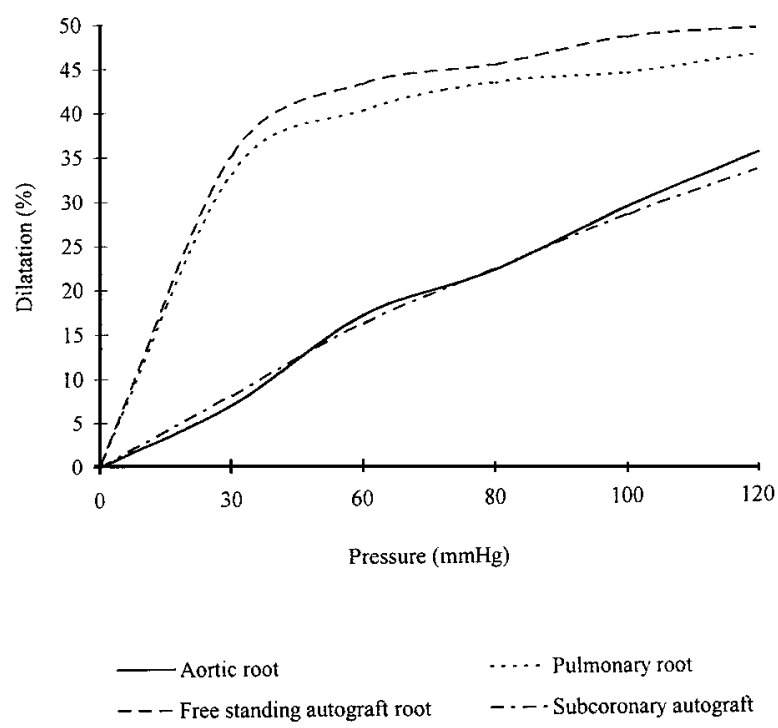

Fig 1. The distensibility of the native aortic and pulmonary roots and the autografts implanted by means of different surgical techniques in the pressure range of 0 to $120 \mathrm{~mm} \mathrm{Hg}$. Confidence limits are as follows (mean percentage of dilatation $\pm \mathrm{SD})$.

ous 4-0 polypropylene sutures in such a way that the autograft's commissures were in alignment with the host's commissural attachment.

After the implantations were completed, the external diameter of the autografts was measured at the sinotubular junction at hydrostatic pressures of $0,30,60,80,100$, and 120 $\mathrm{mm} \mathrm{Hg}$ by means of digital vernier callipers.

Hydrodynamic testing. The pulmonary and aortic roots and the autografts were tested in a pulsatile flow simulator, details of which have been described previously. ${ }^{8}$ The flow simulator consisted of 2 rigid cylindrical test sections for each of the mitral and aortic valves, a compliance chamber, peripheral resistance, and an atrial reservoir. The system was driven by a servo-controlled piston pump. The roots and autografts were mounted in place of the rigid aortic valve section by means of an inflow and an outflow spigot. The aortic roots and autografts were tested at a rate of 72 cycles/min with a stroke volume of $70 \mathrm{~mL}$ for a systemic pressure of $120 / 80 \mathrm{~mm} \mathrm{Hg}$. The pulmonary roots were first tested for a pulmonary artery pressure of $25 / 10 \mathrm{~mm} \mathrm{Hg}$ and then retested for a systemic pressure of 120/80 $\mathrm{mm} \mathrm{Hg}$ at the same rate and stroke volume as for the aortic roots. The pressure difference across the roots was measured directly by a differential transducer, and the flow was measured with an electromagnetic flowmeter positioned downstream to the root. Pressure, flow, pump displacement, and velocity signals were collected digitally for $10 \mathrm{sec}-$ onds at a sampling frequency of $200 \mathrm{~Hz}$ and stored on a disk for analysis by means of an IBM PS/ 2 computer. The data were ensemble averaged to create 1 cycle, and the valve function was analyzed with the use of this averaged waveform. The effective orifice area was calculated by the formula 
Table I. The transvalvular gradient and the effective orifice area of the native aortic and pulmonary roots at systemic and pulmonary pressures

\begin{tabular}{|c|c|c|c|c|}
\hline & \multicolumn{2}{|c|}{ Transvalvular gradient } & \multicolumn{2}{|c|}{ Effective orifice area } \\
\hline & Pulmonary pressure & Systemic pressure & Pulmonary pressure & Systemic pressure \\
\hline Aortic root & - & $6.5 \pm 2.9$ & - & $2.73 \pm 0.47$ \\
\hline Pulmonary root & $7.0 \pm 2.5$ & $4.6 \pm 2.6$ & $2.69 \pm 0.53$ & $2.85 \pm 0.61$ \\
\hline
\end{tabular}

Transvalvular gradients are given in millimeters of mercury (mean \pm SD), effective orifice areas are given in square centimeters (mean \pm SD), pulmonary pressure is $25 / 10 \mathrm{~mm} \mathrm{Hg}$, and systemic pressure is $120 / 80 \mathrm{~mm} \mathrm{Hg}$.

Table II. The transvalvular gradient and effective orifice area of the native aortic and pulmonary roots and the pulmonary autografts implanted by different surgical techniques at systemic pressures

\begin{tabular}{lcc}
\hline & $\begin{array}{c}\text { Transvalvular } \\
\text { gradient }\end{array}$ & $\begin{array}{c}\text { Effective } \\
\text { orifice area }\end{array}$ \\
\hline Aortic root & $6.5 \pm 2.9$ & $2.72 \pm 0.47$ \\
Subcoronary autograft & $7.9 \pm 2.4$ & $2.65 \pm 0.32$ \\
Pulmonary root & $4.6 \pm 2.6$ & $2.85 \pm 0.61$ \\
Free-standing autograft root & $5.3 \pm 3.3$ & $2.81 \pm 0.88$
\end{tabular}

Transvalvular gradients are given in millimeters of mercury (mean $\pm \mathrm{SD}$ ), and effective orifice areas are given in square centimeters (mean $\pm \mathrm{SD}$ ).

$\mathrm{Q} / 51.6 \sqrt{ } \Delta \mathrm{p}$, where $\mathrm{Q}$ is the mean square forward flow in milliliters per second and $\Delta \mathrm{p}$ is the mean pressure drop during forward flow in millimeters of mercury. The effective orifice area is a measure of hydraulic performance based on the effective area for flow derived from the measurements of pressure and flow. It is a more effective way of determining hydrodynamic performance than simply measuring the open area of the valve from the image because the latter does not take account of contraction of the flow downstream of the valve. Valve leaflet movements were recorded with a video camera positioned axial to the flow through the roots to determine the configuration of the open-valve leaflets. A spigot of the same diameter as that of the actual root in its distended state allowed a video recording of the leaflet motions of the entire valve, including the commissural area.

The mean and SD values of the data were calculated. Statistical analysis was performed with the use of the Student $t$ test.

\section{Results}

The distensibility of the fresh aortic and pulmonary roots and the different autografts is shown in Fig 1. In the pressure range of 0 to $120 \mathrm{~mm} \mathrm{Hg}$, the fresh pulmonary roots were much more compliant than the fresh aortic roots. The external diameter of the fresh pulmonary roots increased by $46 \% \pm 8.4 \%$ as the pressure rose from 0 to $120 \mathrm{~mm} \mathrm{Hg}$ as compared with $35 \% \pm$
$7.8 \%$ dilatation for the fresh aortic roots. The pressurerelated dilatation was nearly linear for the fresh aortic roots up to $120 \mathrm{~mm} \mathrm{Hg}$, whereas the pulmonary roots were highly compliant in their normal pressure range (average $33 \%$ dilatation from $0-30 \mathrm{~mm} \mathrm{Hg}$ ), after which they were less compliant (average 13\% dilatation from $30-120 \mathrm{~mm} \mathrm{Hg}$ ). In the physiologic systemic pressure range $(80-120 \mathrm{~mm} \mathrm{Hg})$, the aortic roots dilated by $12 \% \pm 3.5 \%$, whereas the dilatation of the pulmonary root was only $3 \% \pm 1.6 \%$. Implanting the pulmonary autograft in a subcoronary position did not affect the distensibility of the aortic root. The compliance of the free-standing autograft roots was similar to that of the native pulmonary roots.

Table I shows the transvalvular gradient and effective orifice areas of the pulmonary roots under physiologic (pressure of $25 / 10 \mathrm{~mm} \mathrm{Hg}$ ) and systemic (pressure of $120 / 80 \mathrm{~mm} \mathrm{Hg}$ ) conditions. The hydrodynamic parameters were significantly better at systemic pressures than at pulmonary pressures $(P=.01$ for the transvalvular gradient and $P=.02$ for the effective orifice area).

In Table II the transvalvular gradient and effective orifice area results of the native aortic and pulmonary roots are summarized, as well as those of the pulmonary autografts implanted as a free-standing autograft root and in the subcoronary position. The pulmonary roots performed slightly better than the same-sized aortic roots at systemic pressures $(P=.03$ for the transvalvular gradients and $P=.04$ for the effective orifice area). The implantation technique did not have a significant effect either on the pressure gradient $(P=.3$ for the subcoronary implantation and $P=.2$ for the free-standing autograft root) or on the effective orifice area $(P=.4$ for the subcoronary implantation and $P=.3$ for the free-standing autograft root).

All the tested aortic and pulmonary valves, as well as the autograft valves, opened fully in systole and showed very low leaflet deformation. Regurgitation 


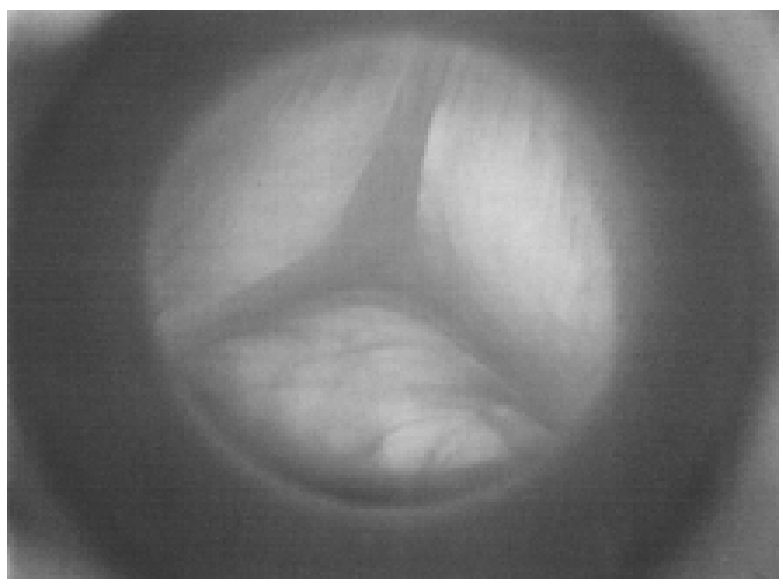

Fig 2. A native aortic valve in its closed position. The edge of the leaflets is thick, producing a strong and wide coaptation surface.

was not found on any of the roots or autografts. Figs 2 to 4 show the valves in their closed position. A good depth of coaptation was seen in the aortic valve, and excess overlap was seen in the pulmonary valve at pulmonary pressures. Coaptation was reduced in the pulmonary valve at systemic pressures. Fig 5 shows the pulmonary autograft valve with a characteristic triangular open orifice with low leaflet bending associated with a dilated root.

\section{Discussion}

Despite the increasing number of autograft implantations and the expanding indications for the Ross procedure, there remain concerns about the ability of the pulmonary valve to withstand aortic pressures. Furthermore, when the free-standing autograft root replacement technique is used, not only the pulmonary valve but also the pulmonary artery wall is exposed to systemic pressures. Thorough morphologic investigation has shown that the structural difference between the aortic and pulmonary roots was minimal: the aortic wall had more elastic lamellae than the pulmonary trunk, and the sinus wall of the aorta was somewhat thicker because of a larger amount of collagen and smooth muscle cells. ${ }^{9}$ The main difference between the aortic and pulmonary valves was that the pulmonary valve had no discrete anulus and was only supported by the right ventricular outflow tract muscle in most of its circumference. ${ }^{10}$ Other authors, ${ }^{11}$ in an experimental model, found that the pulmonary valve leaflets were 3 times stronger than the aortic valve leaflets, although the

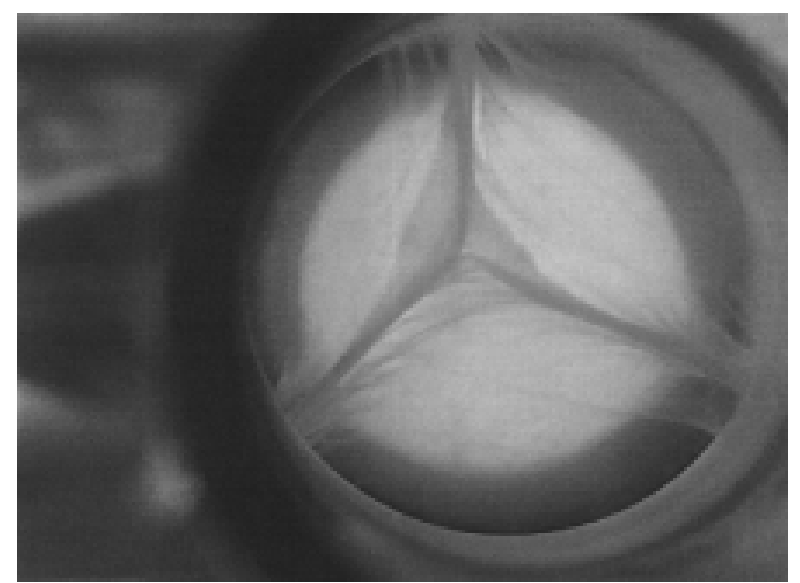

Fig 3. A native pulmonary valve in its closed position at pulmonary pressures. The leaflets are thin and transparent. There is excess valve tissue above the coaptation surface.

pulmonary leaflets were much thinner and contained less collagen than their aortic counterparts. ${ }^{12}$

In our study we investigated the hydrodynamic performance of the pulmonary root at pulmonary and systemic pressures in comparison with the performance of the aortic root. The distensibility of the aortic root was an important determinant of the leaflet opening. ${ }^{13}$ In normal conditions the valve leaflets open fully, producing very low commissural bending strains ${ }^{14}$ and creating a triangular orifice. ${ }^{15}$ The pulmonary root was much more distensible in its normal pressure range, and this phenomenon helped in full valve opening at physiologic conditions. If the pressure increased further, the distensibility of the pulmonary root became limited, and it hardly dilated beyond the pressure of $100 \mathrm{~mm} \mathrm{Hg}$. This 2-phase dilatation of the pulmonary root was an indication that the root was working at abnormal conditions with loss of functional elasticity in the systemic range 80 to $120 \mathrm{~mm} \mathrm{Hg}$, and this may cause concerns about long-term durability. However, this reduction in elasticity of the wall at higher pressures is critical to maintaining valve leaflet function at systemic pressures. If the pulmonary dilatation had been linear at the high dilatation rate seen at low pressures, it would have led to over $100 \%$ dilatation at systemic pressures and almost certainly valvular incompetence. However, the external diameter of the pulmonary root was approximately $13 \%$ bigger at $120 \mathrm{~mm} \mathrm{Hg}$ than at $30 \mathrm{~mm} \mathrm{Hg}$, and this explained the finding that the hydrodynamic performance of the pulmonary valve was found to be better at systemic pressures than at normal pulmonary pressures. ${ }^{15}$ 


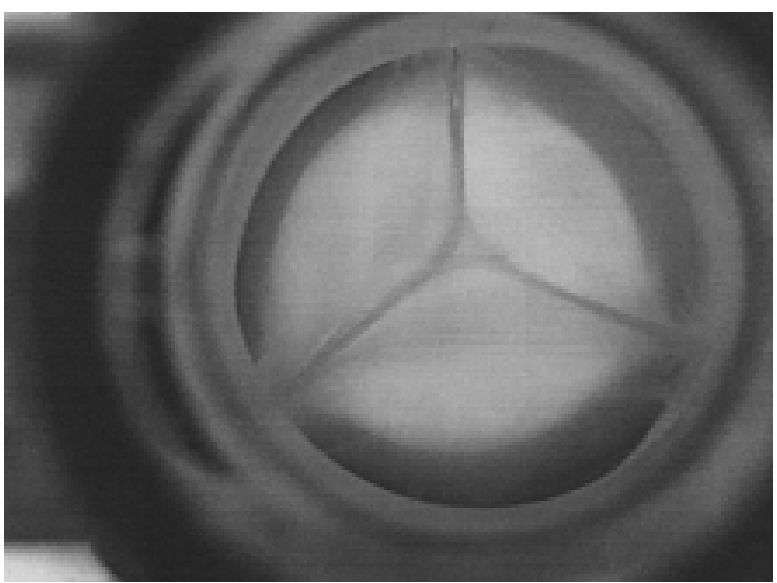

Fig 4. A native pulmonary valve in its closed position at systemic pressures. At higher pressures the coaptation surface displaced to the edge of the leaflets because of the radial extension of the leaflets.

We also investigated the leaflet motion of the pulmonary valve at both physiologic and systemic conditions. We found that although the aortic valve closed at the edges (Fig 2), the porcine pulmonary valve had some excess tissue above the coaptation surface at pulmonary pressures (Fig 3). Our findings also confirmed the results of previous investigators ${ }^{16}$ that at higher pressures the pulmonary leaflets showed wide radial extension, and the coaptation surface was displaced slightly higher to the edge of the leaflets, as at the aortic valve (Fig 4). As a result of the radial extension of the leaflets, the collagen crimps flattened can be seen in a comparison of Figs 3 and 4.

Implanting the pulmonary valve into the aortic root in the subcoronary position by a freehand technique did not change the distensibility of the host aortic root. The valve performance was slightly inferior to that of the native aortic valve, although the difference was not significant. The free-sewn autograft showed a nearly triangular orifice and little open leaflet bending deformation in its fully opened position, as did the aortic or pulmonary valve (Fig 5). That original implantation technique was surgically demanding, and it was very difficult to obtain an anatomic geometry of the valve.

The free-standing autograft root replacement was a surgically less demanding technique, and transferring the pulmonary root en bloc helped preserve the natural geometry of the valve. After implantation, the response of the autograft to pressure was similar to that of the native pulmonary root. The transvalvular gradient was slightly higher, and the effective orifice area was slight-

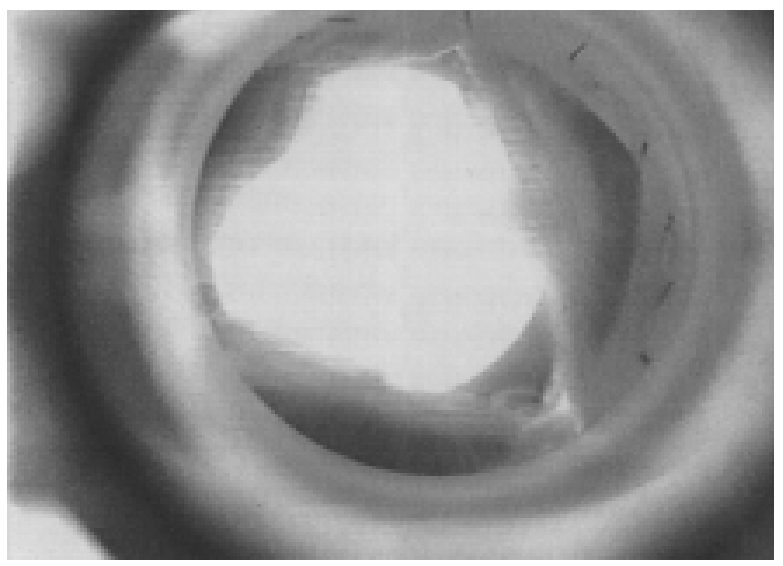

Fig 5. An autograft implanted in subcoronary position in its fully opened position. The leaflets create a triangular orifice, which produces low commissural bending strains.

ly lower on the autografts after implantation than before, but again, the differences were not significant. It is appropriate to calculate the effective orifice area from the flow and pressure difference rather than simply take an area calculator from the 2-dimensional image of the valve because the actual geometry constraining the flow is a complex 3-dimensional structure and further contraction of the flow field and drop on pressure occurs downstream of the valve. The freestanding autograft root also showed full valve opening with very low leaflet deformation.

\section{Conclusion}

Our in vitro results support the anatomic and histologic findings that the pulmonary valve and root are able to withstand systemic pressures without the risk of acute overdilatation of the autograft root. The pulmonary root could not be overdilated at higher pressures because of its nonlinear response on increasing pressures. The pulmonary valve leaflets are easily able to compensate for the extra dilatation of the root at systemic pressures. Neither of the investigated implantation techniques altered the hydrodynamic performance of the autograft adversely.

We thank Devon Darby and John Moore for their kind technical assistance.

\section{REFERENCES}

1. Ross DN. Replacement of the aortic and mitral valves with the pulmonary autograft. Lancet 1967;2:956-8.

2. Geens M, Gonzales-Lavin L, Dawbarn C, Ross DN. The surgical 
anatomy of the pulmonary root in relation to the pulmonary valve autograft and surgery of the right ventricular outflow tract. J Thorac Cardiovasc Surg 1971;62:262-7.

3. Ross DN. Aortic root replacement with a pulmonary autograftcurrent trends. J Heart Valve Dis 1994;3:358-60.

4. Matsuki O, Okita Y, Almeida RS, McGoldrick JP, Hooper TC, Robles A, et al. Two decades' experience with aortic valve replacement with pulmonary autograft. J Thorac Cardiovasc Surg 1988;95:705-11

5. Oury JH. Editorial: The International Registry of the Ross procedure: 1996 results. J Heart Valve Dis 1997;6:333-4.

6. Chambers JC, Sommerville J, Stone S, Ross DN. Pulmonary autograft procedure for aortic valve disease: long-term results of the pioneer series. Circulation 1997;96:2206-14.

7. Elkins RC. Pulmonary autograft: The optimal substitute for the aortic valve? N Engl J Med 1994;330:56-60.

8. Fisher J, Jack GR, Wheatley DJ. Design of a function test apparatus for prosthetic heart valves. Clin Phys Physiol Meas 1986;6:63-73.

9. Hokken RB, Bartelings MM, Bogers JJ, Gittenberger-de Groot AC. Morphology of the pulmonary and aortic roots with regard to the pulmonary autograft procedure. J Thorac Cardiovasc Surg 1997;113:453-61.
10. Gonzales-Lavin L, Metras D, Ross DN. Anatomic and physiological bases for the Ross procedure. J Heart Valve Dis 1996;5:383-90.

11. Gorczynski A, Trenkner M, Anisimowicz L, Gutkowski R, Drapella A, Kwiatkowska E, et al. Biomechanics of the pulmonary autograft valve in the aortic position. Thorax 1982;37:535-9.

12. Gerosa G, Ross DN, Brucke PE, Dziatkowiak A, Mohammad S, Norman D, et al. Aortic valve replacement with pulmonary homografts: early experience. J Thorac Cardiovasc Surg 1994;107:424-37.

13. Brewer RJ, Deck JD, Capati B, Nolan SP. The dynamic aortic root: its role in aortic valve function. J Thorac Cardiovasc Surg 1976;72:413-7.

14. Thubrikar M, Bosher PL, Nolan SP. The mechanism of opening of the aortic valve. J Thorac Cardiovasc Surg 1979;77:863-70.

15. Weerasena N, Lockie KJ, Butterfield M, Fisher J, Kearney JN, Davies GA. The hydrodynamic function and leaflet dynamics of aortic and pulmonary roots and valves: an in vitro study. Eur $\mathrm{J}$ Cardiothorac Surg 1992;6:350-6.

16. Christie GW, Barratt-Boyes BG. Mechanical properties of porcine pulmonary valve leaflets: How do they differ from aortic leaflets? Ann Thorac Surg 1995;60(Suppl 2):195-9.

\section{Bound volumes available to subscribers}

Bound volumes of The Journal of Thoracic and Cardiovascular Surgery are available to subscribers (only) for the 2000 issues from the Publisher, at a cost of $\$ 134.00$ for domestic, $\$ 165.85$ for Canadian, and $\$ 155.00$ for international subscribers for Vol 119 (January-June) and Vol 120 (July-December). Shipping charges are included. Each bound volume contains a subject and author index and all advertising is removed. Copies are shipped within 60 days after publication of the last issue of the volume. The binding is durable buckram with the Journal name, volume number, and year stamped in gold on the spine. Payment must accompany all orders. Contact Mosby, Subscription Customer Service, 6277 Sea Harbor Dr, Orlando, FL 32887,USA; phone 800-654-2452 or 407-345-4000.

Subscriptions must be in force to qualify. Bound volumes are not available in place of a regular Journal subscription. 